\title{
Grade 12 Learners' Conceptual Knowledge in Probability and Counting Principles
}

\author{
Francis Kwadwo Awuah \\ University of South Africa \\ South Africa
}

\author{
Derick Folson \\ Kwame Nkrumah University of Science and \\ Technology, Ghana
}

\begin{abstract}
South African learners' challenge in reaching academic heights in mathematics is widely documented. The country's revision of the Mathematics Curriculum which introduced topics like Probability and fundamental counting principles as compulsory topic in the National Senior Certificate (NSC), South Africa had prior anticipation of a host of challenges towards its implementation. Three years down the line, it has been detected that many teachers experience constrain when they teach the topic, making it difficult for learners to grasp the concepts and effectively solve problems in the topic. The study aims at investigating the achievement levels of grade 12 learners in probability and fundamental counting principles. Participants of the study included four hundred and ninety grade 12 learners from seven different schools in Nongoma educational circuit, South Africa. Data was collected by means of an achievement test and analyzed by the aid of SPSS 23. The study followed the survey research strategy and used the different concepts taught in the topic as a framework of analysis. The findings suggest that learners in this study excelled the most in the use of Venn diagrams to solve probability problem. The result shows that learners' performance in the use of contingency tables to solve probability problems and fundamental counting principles was below expectation. The study had several implications regarding learners' strength and weakness in the topic thus recommendations were made to assist all stake holders on ways of enhancing learners conceptual understating of the topic.
\end{abstract}

\section{Keywords}

Bloom's taxonomy, concepts, grade 12 learners, probability, mathematics, achievements, Matric.

\section{INTRODUCTION}

Mathematics education plays a vital role in human life. This assertion is attested by comments found in different studies like [1], [2], [3] and [4]. However, despite the attached importance to mathematics education, South African learners have over the years bedeviled by incessant poor performance in the subject. Evidence is seen in their performance in both international and local examination. A small minority of South African secondary schools produce most of the country's national senior certificate (NCS) passes in mathematics and science [5]. The shortage of skilled personnel in professions like engineering, applied science, accountancy, architecture, medicine and law are as a result of this poor perfromance since mathematics is an entry requirement into these fields [6]. Different factors have been identified to be the causes of this incessant problem. Prominent amongst them are Teachers' challenges in teaching some topics in the mathematics curriculum [7]. It was not surprising the introduction of concepts like probability and counting principles in the CAPS mathematics document met challenges in its implementation. Reviews of studies done on this topic indicate that many of the studies did not cover the entire content taught in the CAPS document. Others did not highlight the conceptual weakness of the leaners. The data collection used in most of these studies does not give conclusive evidence of their findings. This current study however make use of cognitive test, larger data collection as well as cover the entire content knowledge taught in the topic to investigate on the achievement of these leaners in probability and counting principles.

\section{PROBABILITY AND FUNDAMENTAL COUNTING PRINCIPLES TAUGHT IN THE CURRICULUM AND ASSESMENT POLICY STATEMENT (CAPS)}

Probability is one of the new topics introduced into the South African school mathematics curriculum. In the National Curriculum Statement (NCS), the curriculum that was phased out in 2010, probability was examined in the grade 12 mathematics paper 3 (optional paper) but in the current curriculum, namely CAPS in which probability and statistics form part of 10 main topics [8], all mathematics learners are examined in the compulsory national mathematics paper 1 .

Learners in South Africa encounter the topic probability for the first time in their mathematics studies under the topic data handling in the intermediate phase that is in grade 4 . The CAPS mathematics curriculum has a very strong foundation on probability lessons from grade 4 to grade 9, learners are expected to be fully prepared for the work in the Further Education and Training (FET) phase on the topic since almost all the terminologies and concepts they need at that phase are discussed in lower the grades. The curriculum stipulates that the grade 12 learners should demonstrate knowledge of the following aspects of probability: comparison of theoretical probability and relative frequency; use of Venn diagrams to assist in solving problem; identification of mutually exclusive and complementary events; identification of any two events $\mathrm{A}$ and $\mathrm{B}$, $P(A$ or $B)=P(A)+P(B)-P(A$ and $B)$; identification of dependent and independent events; contingency tables and tree diagrams to solve probability problems and fundamental counting principles.

\section{STUDIES DONE ON PROBABILITY IN SOUTH AFRICA AND BEYOUND}

Studies done on probability have been centralised around identifying learners' errors and misconceptions, teacher content knowledge problems associated with the teaching and learning of the topic and many others. [9] investigated on the teaching and learning of data-handling in primary schools in 
South Africa. The study examined factors such as inability of teachers to explain and understand the CAPS; Pedagogical Content Knowledge (PCK); Subject Matter Knowledge (SMK) and Pedagogic Knowledge (PK), Lack of mathematics problem solving skills, language difficulties, inadequate statistical qualification and poor pre requisite skills, fact and concepts. Similarly, [10] studied the problem encountered in the teaching and learning of statistics among grade 11 learners in South Africa. Her findings revealed that the learners experience difficulties interpreting probability terminologies, had inadequate text books, in service programs which did not cover statistical topics or which did not pay adequate attention to probability and lastly teachers failure to attend those in-service teacher workshops were the cause of the teachers difficulties in the topic. The causes of learner difficulties were inadequate teaching of statistics topics in previous grades, teacher's lack of content knowledge, inadequate learning materials and learners' inability to use the statistical function mode on their calculators, and learner's lack of conceptual knowledge of certain topics in statistics.

[11] study on the teaching experiment on 14-15 years among Spanish learners revealed that teaching had significant impact on learner performance.in comparison one can clearly see that the studies done outside South Africa showed positive effect of teaching on learner performance however the research done in South Africa showed that teaching had no effect on learner performance. This is because after the leaners had been taught the topic the results they had on writing the post test was not statistically significant. The implication of this is that teachers in South Africa find some concepts in probability difficult to explain to learners. [12] study on grade 10 learners' errors and misconception in South Africa revealed five main categories of errors and misconceptions namely difficulty with construction of visual representations, improper distinction between simple and compound events application of impropriate routines errors associated with familiarity and misinterpreted language. According to the Mutara, the inappropriate choice of representations was caused by misinterpretations of probability terminology. The learners in the study committed fewer errors where the task provided representations and also they were more confident in using tree diagrams representations despite the fact that they struggle to construct them as compared to the use of Venn diagrams, outcomes listings and matrix representations. Despite the extensive research done in this study, it was silent on fundamental counting principles and concepts like the dependant and independent events. However the researchers believe this was because these concepts are not taught in the grade 10 mathematics syllabuses. This study would look into the entire probability concepts taught in CAPS document.

\section{MATHEMATICS TEACHERS AND PROBABILITY IN SOUTH AFRICA}

Mathematics teachers' are the implementers of the mathematics curriculum, however, research literature has revealed that a significant number of mathematics teachers in South Africa, encountered data handling and probability for the first time in 2006 when the topic became part of the school mathematics in Further Education and Training (FET) band [13]. Earlier probability was treated as only a component of statistics in tertiary institutions in South Africa [10]. This is an indication that most South African teachers who are teaching mathematics in the secondary schools have never studied the topic when they themselves were at secondary school or college of education. The question then is how can one give what he/she has not got? [10] reports of in-service training organised by both government and non-governmental organisations just to enhance on teachers conceptual understanding in data handling and probability because teachers consider these topics challenging to teach however, [14] investigation on teacher knowledge and confidence in grade 8 and 9 data handling and probability in South Africa revealed that despite in-service training that is organised for teachers on topic probability, almost all the teachers that took part in the study showed low levels of confidence in teaching statistics and probability particular when it comes to applying statistical knowledge. This study is in consonance with [10] in the line of teachers' weakness in teaching the topic probability and counting principle. However the instruments used does not provide a conclusive evidence of teachers statistical and probability knowledge. Classroom observation, diagnostic test followed by interviews might have given a more detail information on teachers' perspective regarding the teaching of the topic however what the research failed to highlight is the aspect of probability that teachers' find difficult to teach. If this knowledge is highlighted it will assist stake holders on the kind of support that must be given to these teachers. Knowing the teachers' content knowledge is of much importance in teaching particularly when it comes to addressing learners' weakness in a subject [15].

Table 1: Average results of grade 12 learners end of year national examination in probability and fundamental counting principles in South Africa

\begin{tabular}{|c|c|c|c|}
\hline Topic & $\mathbf{2 0 1 4}$ & $\mathbf{2 0 1 5}$ & $\mathbf{2 0 1 6}$ \\
\hline Probability & $39 \%$ & $28 \%$ & $65 \%$ \\
\hline Counting principle & $29 \%$ & & $2 \%$ \\
\hline $\begin{array}{c}\text { Average percentage } \\
\text { whole examination }\end{array}$ & $53,5 \%$ & $49,1 \%$ & $51,1 \%$ \\
\hline
\end{tabular}

Table 1 shows South Africa's learners' average performance in probability and counting principles since its inclusion in Mathematics curriculum in 2014. According to [16], [17] and [18], these topics were among those in which learners' achievement was relatively poor. The report indicates that although some aspects were answered adequately, other aspects were below standard. The report attributes learners' poor performance in answering probability questions to the fact that the topic is still new to a number of teachers. This affirms the point that most South African teachers find the task of teaching the concept of Probability and counting principles in the mathematics classroom to be arduous and exceptionally demanding.

Knowing learners' achievement in terms of conceptual understanding may be a way of identifying their weakness in other to address it .It is against this background that the current study was undertaken with the objective of identifying the achievement levels of learners according to the different concepts of the topic enshrined in the mathematics curriculum.

The research questions addressed are as follows:

1. What are grade 12 learners' achievement in the different concepts taught in probability and fundamental counting principles

2. What are the strength and weakness among the different concepts taught in probability and fundamental counting principles 


\section{CONCEPTUAL FRAMEWORK}

The study is underpinned by the different concepts taught in probability and fundamental counting principles as enshrined in CAPS mathematics document. The concepts were categorized into the following

1. Mutually exclusiveness, inclusive, exhaustiveness complementary and the addition law

Mutually exclusive and inclusive are defined on the bases of whether events can occur simultaneously or not. That is to say the events intersect or are disjoint. For example if the events $\mathrm{A}$ and $\mathrm{B}$ are mutually exclusive then $P(A$ and $B)=0$ however if the events $\mathrm{A}$ and $\mathrm{B}$ are inclusive then $P(A$ and $B) \neq 0$. Learners are expected to be able to state and use the addition law when events are mutually exclusive or inclusive. Events are exhaustive when they are complementary and mutually exclusive. Learners are expected to be able to identify and use this equation in solving probability problems. Complementary events add up to one thus Probability of A complement denoted $P(A)^{\prime}$ is defined as $P(A)^{\prime}=1-P(A)$.

2. Dependent events, independent events and the product rule Two events A and B are said to be independent if the outcomes of the one event does not affect the probability of another event occurring. If the outcome of one event changes the probability of an event occurring then the event is said to be dependent. When events $\mathrm{A}$ and $\mathrm{B}$ are independent $P(A$ and $B)=P(A) \times P(B)$. On the bases of selection with and without replacement, learners are expected to know when events are dependent or independent regarding the sample space and number of events after each selection is made. The use of the product rule is inevitable in this concept.

3. The use of tree diagram to solve probability problems

The tree diagram, which is the normally referred to as a decision tree is studied at this level. Learners are expected to know the number of trials (experiments) referred to the number of trees (different decisions to be made) as well as the different options relating the number of branches. Leaners are required to know the different probabilities at each stage of the selection process, the product rule as well as the meaning of the word "OR" and "AND" in solving problems with this category is of great importance.

\section{The use of Venn diagram to solve probability problems} The Venn diagram is a graphical way of representing sample spaces and its events.

Learners are expected to be able to represent information on the Venn diagram. The use of the Venn diagram requires learners to understand words like A only, A and B, B only, complement of events total probability, $A \cap B$ and be able to put them in their respective regions on the Venn diagram. The words "OR" and "AND" are supposed to be clearly explained to learners. The addition law which is gotten from this concept is expected to be proven to learners.

5. The use of contingency tables to solve probability problems.

The two way contingency table, are statistical tables that show the relationships between two or more variables. They are often used to determine if events are independent. Learners are supposed to understand the different rows and columns on the table and be able to read values from this table as well as use it to solve problems.

6 . Fundamental counting principles.
The fundamental counting principles are a principle used to determine the number of different ways to accomplish different task. The fundamental counting principles introduce words like factorial which helps in the counting. The CAPS document has aligned different concepts learners are supposed to study basically arrangement and selection. Leaners are expected to know all the techniques needed to solve these problems. Learners are expected to be taught about four main rules in this concept.

Rule1: This rule states that if an operation can be done in $\mathrm{m}$ ways and a second operation can be done in $n$ ways then the total possible different ways in which both operations can be done is $(m \times n)$. Under this rule, learners are expected to be learning arrangement of objects when the objects are repeated or not repeated. For example: consider the word RANDOM. You are required to form different six letter word arrangements using the letters of the word RANDOM. How many possible word arrangements can be made if the letters may be repeated? or the letters may not be repeated?

Rule 2: This rule states that the number of arrangement of $n$ things take in $n$ ways is $n !$. For example in how many ways can 5 different people be seated in the first 5 seats in at a concert?

Rule 3: the rule states that the number of arrangements of $n$ different things taken $r$ at a time is given by $n ! /(n-r)$ !. For example: In how many ways can 6 vacant places be filled by 9 different people? Questions on this concept in most cases are followed by certain restrictions in follow up questions. For example given the digits $0-7$, if one is to make a 4 digit code, how many codes are numbers greater than 4000 and are exactly divisible by 2 . To answer this question, learners are expected to have a fair idea on the divisibility rules. It must be noted that the concept involves the use of permutations however the word permutation is silent in the mathematics examination guidelines of the CAPS document.

Rule 4: the number of $n$ different ways that $n$ letters can be arranged where $m_{1}$ of the letters are identical, $m_{2}$ of the letters are identical, $m_{3}$ of the letters are identical..... $m_{n}$ of the letters are identical is given by $n ! /\left(m_{1} ! \times m_{2} ! \times m_{3} ! \times \ldots \times m_{n} !\right)$. For example: consider the word NEEDED

How many word arrangements can be made with this word if

1. The repeated letters are treated as different letters?

2. The repeated letters are treated as identical?

\section{METHODOLOGY}

\subsection{Participants and research approach}

To address the research problem, a quantitative approach was undertaken to ascertain the grade 12 learners' achievement in probability. Survey research design was employed and data was collected using a cognitive test. The participants were a sample of 490 learners from seven schools conveniently sampled from a population of ten schools in the educational circuit of Nongoma. The remaining three schools opted out due to circumstances beyond their control.

\subsection{Instrument and Development of test}

The instrument for the data collection was an achievement test on probability and fundamental counting principles. The construction of the test was guided by [19] and the grade 12 mathematics examination guidelines.

\subsection{Validity of Instrument}

Content validity measures the extent to which the content of the instrument covers the extent and depth of the topics it 
intends to cover. [20] noted that content validity is useful when evaluating educational test and research questionnaires. According to [21], it can be done by a panel of judges who are expert in the field to rate the item to content congruence according to laid down criteria. In this regard the content validity of the instruments used in the study was done by three experts in the field of mathematics education. They were asked to moderate the questions to ascertain their alignment of the content as stipulated in the examination guide lines of. These experts evaluated the mark allocation of each question, the language used and also the content covered. They judged the level of alignment of each question against the curriculum by using a 3 -point rating scale $(1=$ not aligned; 2 = fairly aligned; $3=$ much aligned). All questions were retained because they all had an average rating of 2.5 .

According to [22] construct validity give evidence that the construct measured by the test is required for success on the criterion of interest and that the specific test under consideration is a good measure of the theoretical construct or trait. The experts employed in the measurement of the content validity evaluated the construct validity of these instruments also. Their judgment gave evidence that the instruments were good measure of what they intended to measure.

\subsection{Reliability of Instrument}

[23] documented that for research instrument to be reliable it must demonstrate consistency if it is administered to similar group of respondents in a similar context it will produce similar results. It must however be noted that a test can be highly reliable yet not measure what is purported to measure. It is therefore necessary to have a good understanding of reliability to ensure appropriate testing of the instrument. [24] noted that when a test is reliable it can be generalized in many different ways. The test-retest method was used to ascertain the reliability of the instrument. The test-retest method was used to ascertain the reliability of the instrument. The Cronbach alpha formula was used in testing for the reliability and a reliability coefficient of 0.822 was obtained. This value was found to be an appropriate measure [25]. The marking was moderated and the graph below shows the inter rater reliability of the scores.

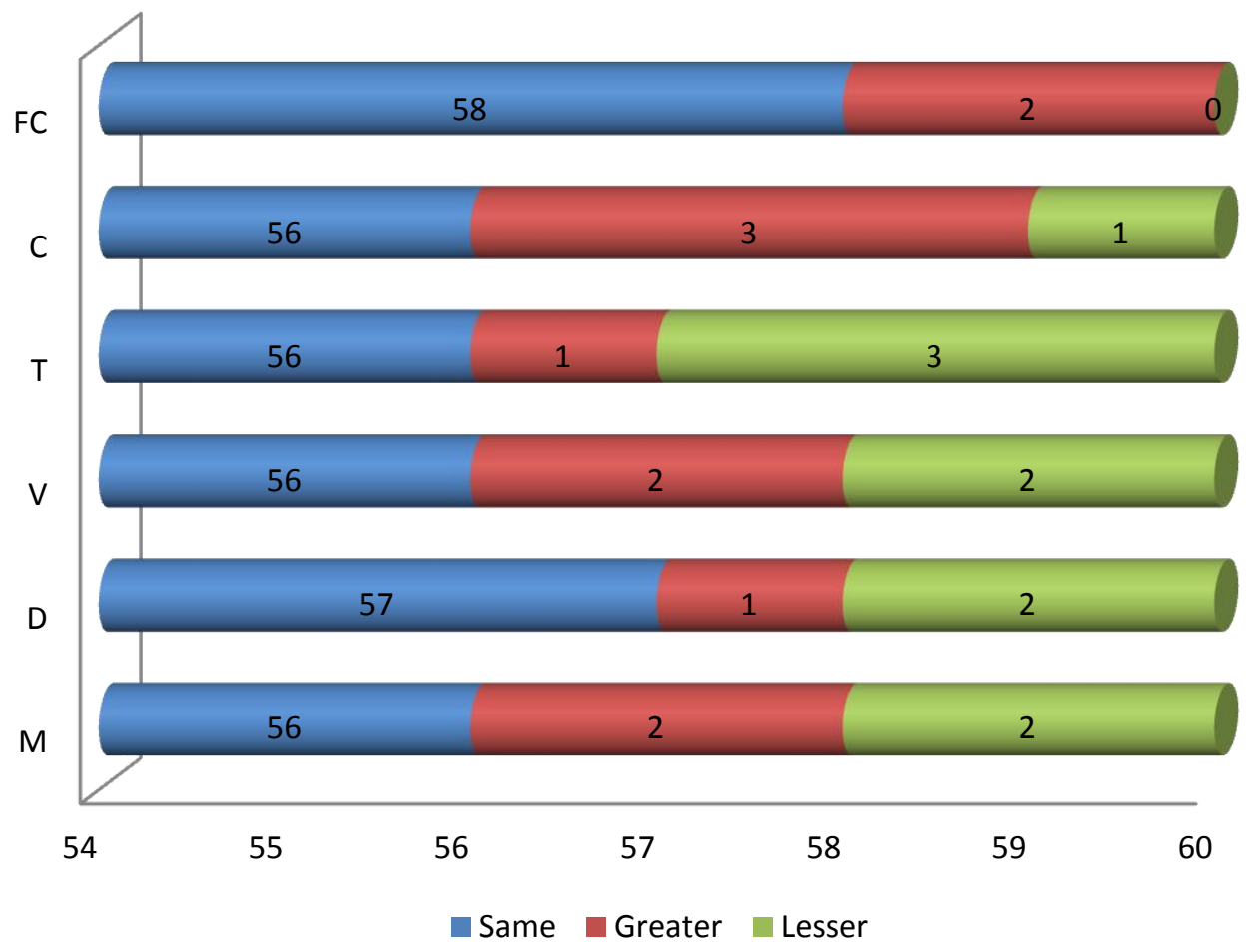

Fig. 1: Inter rater reliability scores.

Figure 1 indicates that averagely, 94\% of the scores of the marker who was the researcher and the moderator was the same, $2.8 \%$ of the score of the moderator's scores was greater than that of the marker and $3.2 \%$ of the moderator's scores were smaller than the marker.

\section{DATA ANALYSIS}

In the data analyses, various descriptive statistics in learners' performance according to content knowledge were presented in this section. SPSS 23 was used for the data analysis. The statistics included the averages, minimum mark scored, maximum mark scored, the standard deviations, frequencies and percentages of participants. Frequencies of number of learners who achieved at certain percentage level for the combined participant was presented. Frequencies of learner achievement was give based on the South Africa's, DoE performance levels were given.

\subsection{Descriptive analysis on learners' conceptual abilities in probability and counting principles}

Learners were made to write a test on probability and counting principles. The scripts were marked and their performance analyzed according to the different concepts taught in probability and counting principles of the grade 12 mathematics curriculum. 
Table 2: Descriptive Statistics

\begin{tabular}{|c|c|c|c|c|c|}
\hline & N & Minimum & Maximum & Mean & Std. Deviation \\
\hline mutually exclusive, inclusive, addition law (M) & 490 & 1 & 11 & 5.38 & 2.741 \\
\hline dependant/independent/product rule ( D) & 490 & 1 & 10 & 4.45 & 2.196 \\
\hline use of Venn diagram mark (V) & 490 & 1 & 10 & 7.06 & 2.580 \\
\hline use tree diagram (T) & 490 & 1 & 11 & 3.88 & 1.810 \\
\hline Fundamental counting principles (C) & 490 & 1 & 11 & 3.16 & 2.327 \\
\hline use of contingency table (FC) & 490 & 1 & 7 & 3.11 & .659 \\
\hline grand total (GT) & 490 & 1 & 6 & 3.22 & 1.075 \\
\hline Valid N (listwise) & 490 & & & & \\
\hline
\end{tabular}

The results shows that the mean score $(\mathrm{M}=5,38 ; \mathrm{D}=5,32 ; \mathrm{V}=7.32 ; \mathrm{T}=3,88 ; \mathrm{FC}=3.16 ; \mathrm{C}=3.11 ; \mathrm{GT}=3.22)$

Table 3: Frequency distribution of learner performance in the different concepts taught in probability and counting principles

\begin{tabular}{|c|c|c|c|c|c|c|c|c|c|c|c|c|c|c|}
\hline \multirow{2}{*}{$\begin{array}{l}\text { Mark range Dol } \\
\text { Performance } \\
\text { level }\end{array}$} & \multicolumn{2}{|c|}{$M$} & \multicolumn{2}{|c|}{ D } & \multicolumn{2}{|c|}{$\mathbf{V}$} & \multicolumn{2}{|c|}{$T$} & \multicolumn{2}{|c|}{ C } & \multicolumn{2}{|c|}{ FC } & \multicolumn{2}{|c|}{ GT } \\
\hline & $\mathrm{F}$ & $\%$ & $\mathrm{~F}$ & $\%$ & $\mathrm{~F}$ & $\%$ & $\mathrm{~F}$ & $\%$ & $\mathrm{~F}$ & $\%$ & $\mathrm{~F}$ & $\%$ & $\mathrm{~F}$ & $\%$ \\
\hline $0-29$ & 151 & 30.9 & 124 & 25.3 & 61 & 12.5 & 128 & 26.2 & 313 & 63.9 & 418 & 85.3 & 274 & 55.9 \\
\hline $30-39$ & 41 & 8.4 & 31 & 6.3 & 18 & 3.7 & 218 & 44.5 & 35 & $\begin{array}{l}7.1 \\
\end{array}$ & 62 & 12.7 & 170 & 34.7 \\
\hline $40-49$ & 76 & 15.5 & 34 & 6.9 & \begin{tabular}{l|l|}
64 \\
\end{tabular} & 13.1 & 66 & 13.5 & 27 & \begin{tabular}{l|}
5.5 \\
\end{tabular} & 4 & 0.8 & 43 & 8.8 \\
\hline $50-59$ & 32 & 6.5 & 123 & 25.2 & 53 & 10.8 & 51 & 10.4 & 50 & 10.2 & 2 & 0.4 & 3 & 0.6 \\
\hline $60-69$ & 67 & 13.6 & 96 & 19.6 & 53 & 10.8 & 12 & 2.4 & 46 & 9.4 & 4 & 0.8 & 0 & 0 \\
\hline $70-79$ & 25 & 5.1 & 59 & 12 & 57 & 11.6 & 9 & 1.8 & 16 & 3.3 & 0 & 0 & 0 & 0 \\
\hline $80-100$ & 98 & 20.0 & 23 & 4.7 & 184 & 37.5 & 6 & 1.2 & 3 & 0.6 & 0 & 0 & 0 & 0 \\
\hline TOTAL & 490 & 100 & 490 & 100 & 490 & 100 & 490 & 100 & 490 & 100 & 490 & 100 & 490 & 100 \\
\hline
\end{tabular}

$\mathrm{F}=$ frequency, $\%=$ percentage

Table 3 shows the frequency distribution of learners in the different concepts according to the Department of Education performance levels.

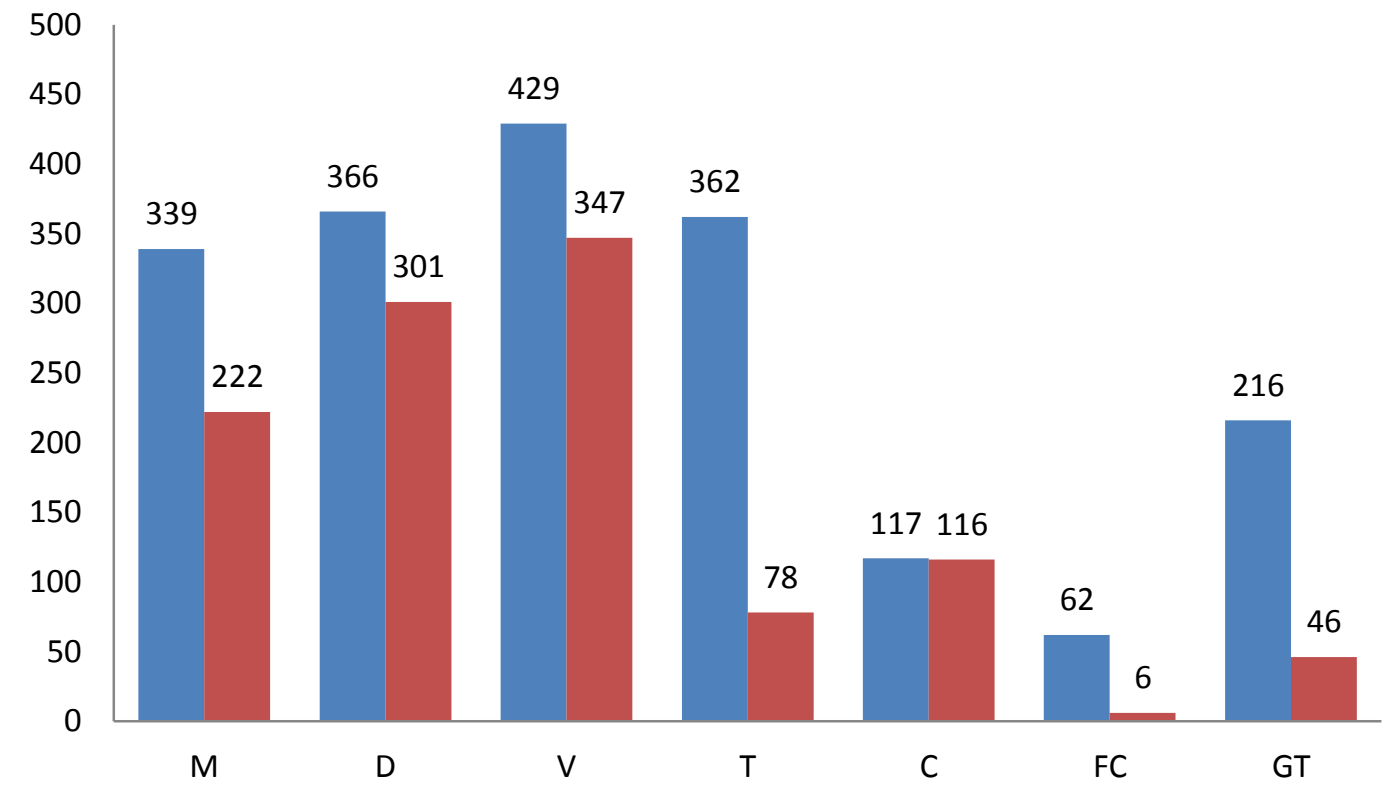

Number of learners that passed at $30 \% \quad$ Number of learners that passed at $50 \%$

Fig. 2: Frequency of learners' performance per content knowledge in the topic

Figure 2 shows the number of learners out of the total 490 participants, who achieved at $30 \%$ and $50 \%$ at the different content knowledge.

\section{DISCUSSION}

The first research question was: what are grade 12 learners' problem solving skills according to the different concepts in the grade 12 Mathematics curriculum. The results shown in table 2, table 3 and figure 2 indicates that most of the learners excelled in the use of Venn diagrams to solving probability problems. These findings contradicted the findings of [10] and [12] who reported that learners struggled with the use of Venn diagrams to solve probability problems. A greater number of the learners were able to illustrate the information given on the question on the Venn diagram. Comparing the use of the addition formula to solving probability problems and the use 
of the Venn diagram to solve problems, the study revealed that most learners were confortable in the use of Venn diagram than the addition formula. It is worth noting that those that could not score the total marks had few problems with identifying the correct region to put the figures on the Venn diagram. This is likely to be a problem of misunderstanding of probability notations like union and intersection as noted by [10] that learners found interpretation of probability notation a challenge. The fundamental counting principle was the most poorly answered question in this study. This was consistent with the findings of [10]'s study that identified that teachers find the teaching of the fundamental counting principles as a challenge. One is tempted to believe that the problems learners are facing in solving questions on fundamental counting principle has its roots from the weak content knowledge and poor pedagogical know how of teachers teaching these learners. Furthermore, the performance of the learners is in consonance with the South Africa's national diagnostic report [16], [17] and [18]. The use tree diagrams to solve probability problems were fairly answered however they were not totally void of errors and misconceptions. [12] however reports that learners were not confident with the use tree diagrams. Reviews of literature on learners understanding on these concepts indicate that the literature on learner performance on these concepts is scanty. This notwithstanding a few found in the literature particularly in the national diagnostics reports, South Africa are consistent with the findings of this study. However with the exception of the use of contingency tables and fundamental counting principles which seemed to be extremely difficult for learners according to this study, researchers are of the opinion that learners understanding in the remaining concepts are not beyond correction. With good teaching practices like giving constructive feedbacks learners are likely to do better as argued by [26]. The concept, fundamental counting principle requires serious and immediate attention since it appears that the problem has got to do with teacher content knowledge. [14] claims teachers were still not confident in solving probability questions even after organizing content workshops for them. [10] asserts that the teachers fail to attend these inservice training workshops organized for them. This might be the reasons why teachers still find the task of teaching probability and counting principle challenging thus learners' inability to understand the concepts. The curriculum gives solid foundation to these learners in the lower grades. Researchers are of the opinion that if teachers would attend intensive workshops organized for them on these areas where they lack knowledge it will enhance the performance of learners in the topic as suggested by [11] that if content workshops are organized for teachers it will have a rippling effect on learners' performance.

\section{CONCLUSION AND RECOMMENDATION}

\subsection{Conclusion}

In this article researchers used the different concepts taught in the probability and counting principles in the mathematics curriculum of the FET phase to identify the conceptual knowledge of grade 12 learners' in solving probability problems in South Africa. The findings of the study suggest that the learners used in the study were weak particular in the use of contingency tables to solve probability problems, the use of tree diagrams to solve probability problems and fundamental counting principles as compared to the other concepts in the CAPS. Learners' performance in the use of Venn diagram to solve probability problems was encouraging however it must be noted that teachers need to drill learners more on the basic definitions and terminologies since the number of learners that were able to get the total marks in these questions was not appreciable. The findings of the study have implication which suggests that teachers need to be assisted in their conceptual knowledge of the use of contingency tables to solve probability problems as well as the fundamental counting principle since learners performed abysmally in these concepts. Future studies should consider conducting interviews to look into the causes of learner weaknesses in the different concepts taught in probability and counting principles of the CAPS document.

\subsection{Recommendation}

The findings of this study provide evidence with practical implications. First, researchers recommend regular contentspecific professional development for all teachers, especially on newly introduced topic like probability and counting principle. This would help teachers to be more effective in teaching the content of the topic. Secondly, the findings of this study make a case for in-depth study of teachers' classroom practices in teaching probability and counting principle particularly with teachers teaching mathematics in the lower grades. Teachers are to pay attention to basic definition of terminologies as well as engage learners in more activities to assist them in getting use to most of terms and concepts used in the topic. Teachers are also been advised to avail themselves for workshops that will enhance their knowledge and teaching methodologies in concepts like the contingency tables, tree diagrams and the fundamental counting principle.

\section{REFERENCES}

[1] Tella, A. (2008). Teacher variables as predictors of academic achievement of primary school pupils. Mathematics International Electronic Journal of Elementary Education 1(1) 17-33.

[2] Pandor,N. (2006). Not where we want to be. Address by the minister of education on the release of the 2006 senior certificate examination results. Cape town parliament,26 December, 2006.

[3] Ojose, B. (2011). Mathematics literacy: Are we able to put the mathematics we learn into everyday use? Journal of Mathematics Education 4(1), 89-100.

[4] Unodiaku, S.S. (2012). Development and validation of mathematics readiness. Test for senior secondary school student. African journal of science technology and mathematics education 2(1), 57-71.

[5] Center for Development and Enterprice, CDE (2010). The math's and the science performance of South Africa's public schools: some lesson from the past decade. Available at www.cde.org.zaAssessed 10 September 2017.

[6] Siyepu, S. (2013). The zone of proximal development in the learning of mathematics. South African Journal of $\begin{array}{llll}\text { Education, 33(2).Art no 714, } 13 & \end{array}$ pageshttp://www.sajournalof education.co.za

[7] Atagana, H.I., Mogari, L. D., Kriek, J., Ochonogor, E. C., Ogbonnaya, U. I., Dhlamini J. J., \& Makwakwa, E. G. (2010). An intervention into teachers' and learners' difficulties in some topics in mathematics, science and technology: A report of the ISTE 2010 winter school. The Institute for Science and Technology Education, University of South Africa. Pretoria, South Africa. 
[8] Department of Basic Education. (2011). Curriculum and assessment policy statement (CAPS). Pretoria: Government Printer

[9] Adu, E. O., \& Gosa L. J. (2014). The Teaching and Learning of Data- Handling in Primary Schools: South African Experience. Mediterranean Journal of Social Sciences, 5(23). 814-819.

[10] Makwakwa, E. G. (2012). Exploring problems experienced by grade 11 mathematics in the teaching and learning of statistics.Masters dissertation, University of South Africa, Pretoria, South Africa retrieved from http://hdl.handle.net/105009483 .

[11] Saenz, C. (1998). Teaching probability for conceptual change educational studies in mathematics, 35, 233-254.

[12] Mutara, L. (2015). Exploring grade 10 learners' errors and misconceptions involved in solving probability problems using different representations. Phd thesis, University of the Witwtersrand, Johannesburg, South Africa.

[13] South African Broadcasting Corporation (2013, April 19). Shortage of maths, science teachers a problem in South Africa. $S A B C$. Retrieved from http://www.sabc.co.za/news/a/a212b8004f510b95be78bf 1e5d06aea0/Shortage-of-maths,-science-teachers-aproblem-in-SA--20130419.

[14] Wessels ,D.C.J. \& Kwari, R. (2003). The nature of problem solving in mathematics: traditional vs contemporary view Journal for Christian Scholarship, 39 (192), 69-93.

[15] Ogbonnaya, U.I. (2010). Improving the teaching and learning of parabolic functions by the use of the information and communication technology. African Journal of Research in MST Education, 14 (1), 46-60.
[16] Department of Basic Education, (2014). National senior certificate examination diagnostic report. Pretoria: Government Printing Works.

[17] Department of Basic Education, (2015). National senior certificate examination diagnostic report. Pretoria: Government Printing Works.

[18] Department of Basic Education, (2016). National senior certificate examination diagnostic report. Pretoria: Government Printing Works.

[19] Bloom, B. S. (1956). Taxonomy of educational objectives handbook: The cognitive domain. New York: David McKay.

[20] Lewis, R. (1999).Teachers coping with the stress of classroom discipline. Social psychology of education. 3(3), 155-171.

[21] Osterlind, S.J.(1989).Judging the quality of test items: Item analysis. In Constructing test items. :259-310) Springer Nertherlands.

[22] Bennett G.K., Seashore, H.G., \& Wesman, A.G. (1991). Technical manual for the differential aptitude test. Chicago: Psychological Corporation.

[23] Cohen, L., Manion, L.,\& Morisson. K. (2013). Research methods in education. Routledge.

[24] Salvia ,J \& Y ssldyke, ,J E. (2001). Assessment. Boston, MA: Houghton Mifflin.

[25] Hof, M. (2012). Questionnaire evaluation with factor analysis and cronbach's alpha: An example. Retrieved from: http://www.let.rug.nl/nerbonne/teach/rema-statsmeth-seminar/learner-papers/MHofQuestionnaireEvaluation-2012-CronbachFactAnalysis.pdf (Accessed on 10 March 2016)

[26] Naroth,C (2010). Constructive teacher feedback for enhancing learner performance in mathematics doctoral thesis, university of free state, Free state, South Africa. 